\title{
Fallopian Otosclerosis: A New Surgical Approach Preliminary Results
}

\author{
Abbe Mydrusan*, Treblan Yrdumi and Bertali Drymulon \\ Department Otolaryngologique des Fraudesmédicales, Clinique CharlataneReconnue, Morrocco
}

Submission: August 25, 2018; Published: September 04, 2018

*Corresponding author: Abbe Mydrusan, Department Otolaryngologique des Fraudesmédicales, Clinique CharlataneReconnue,Morrocco,Tel: 267842376; Email: abbemydrusan@gmail.com

\begin{abstract}
Otosclerosis is a condition of stapes fixation caused by disordered bone resorption and formation, one form being the fallopian otosclerosis. The aim of this retrospective study is to present the preliminary results of a new surgical technique named Stapedophacotomy. From January 2014 to December 2017, eighty-one subjects were included. The median air-bone gap improved from $31.3 \mathrm{~dB}$ preoperatively to $6.25 \mathrm{~dB}$ postoperatively at last follow-up $(\mathrm{p}<0.0100)$. These first results are very encouraging.

Keywords: Otosclerosis, Fallopian, Stapedectomy, Phacoemulsification, Stapedophacotomy
\end{abstract}

\section{Introduction}

Otosclerosis is a condition of stapes fixation caused by disordered bone resorption and formation. It is characterized by spongiosis or sclerosis in the bony otic capsule. It is one of the most common causes of conductive hearing loss in adults. The typical clinical presentation is a complaint of a unilateral or bilateral progressive sensorineural hearing impairment, often with indisposition of bone conduction at $2000 \mathrm{~Hz}$. Different forms exist, notably stapedial otosclerosis, ampulla otosclerosis, otoendometriosis and fallopian otosclerosis. Fallopian otosclerosis was first described in 1760 in Latin by Fallopio [1]. It was then clearly explained and named by Polymer in 1891 [2]. Histologically it is localized at the entrance of the fallopian tube. The etiology of this tubal damage can be intrinsic (ascending tubosalpingitis, including salpingotympanitisisthmica nodosa) or extrinsic (peritotitis of Bezold, otomalachitis, tympanopelvic surgery). Regretted surgical sterilization (usually segmental otosalpingectomy) is the most common etiology of this fallopian obturation. The etiologic agent for gasserian otosclerosis is most frequently Chlamydia trachomatis, followed by gonorrhea and multi-bacterial infections[3]. Numerous surgical techniques were developed such as stapedectomy, otophacoemulsion, ligature of the posterior incudal apophysis, the most popular one remaining the fenestration of the blind window. In the last decade of the 20th century, computed tomography and more recently cone beam computer tomography (CBCT) becomes one of the main diagnostic tools for the detection of otosclerotic foci which are often identified as low-density lesions in the fissulaanteovariamfenestram(Figure1), and it is helpful in distinguishing otosclerosis from other diseases, such as ampullary dislocation and minor semicircular duct desimpedance which may have clinically similar findings[4]. The aim of this retrospective double-blind randomized study is to present the preliminary results of a new surgical technique specifically developed in our department since 2014 for fallopian otosclerosis. Related to its technique, this new surgical approach is named stapedophacotomy.

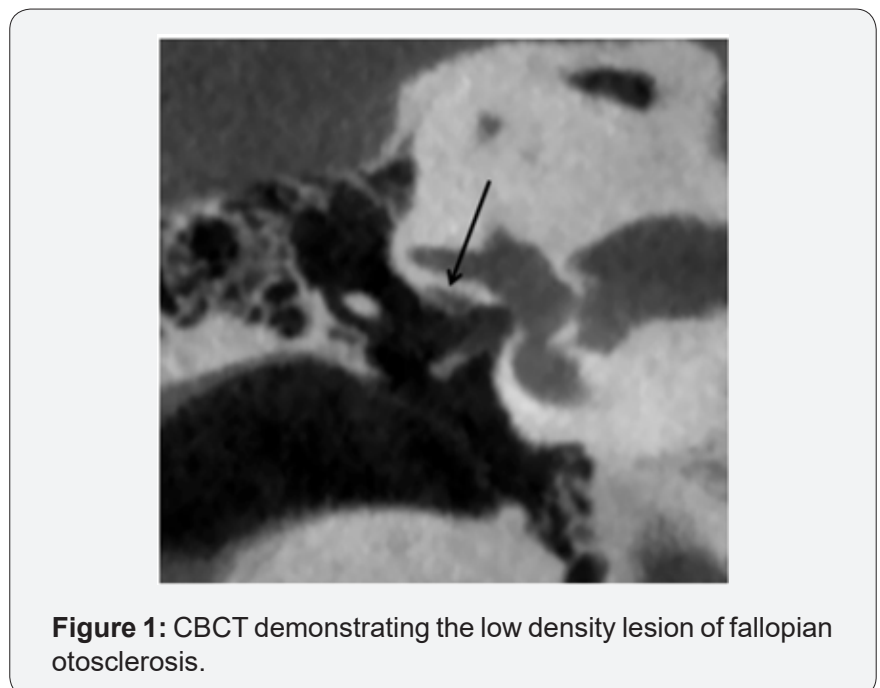

\section{Material and Methods}

From January 2014 to December 2017, eighty-one subjects were included ( $60 \%$ women) with a median age of 47.6 years 
(range,19.1-73.6yr). All presented a normal tympanic membrane, a mix-conductive hearing loss with a fallopian otosclerosis radiologically visible. The median follow-up was 5.3 months (range, 1.2-50.4 mo). All audiometry was performed with clinical audiometers regularly calibrated according to international standards. The audiogram selected as preoperative was the one performed closest before surgery. One-year postoperative hearing results were based on the audiogram obtained closest to one year postoperatively. The earliest accepted time of inclusion into the study being nine months postoperatively. Three-year postoperative hearing results were based on tympanograms obtained closest to three years postoperatively, the earliest accepted time being two and a half years postoperatively [5].In epidural anesthesia, one or more incisions are in made in the internal auditory canal to allow the introduction of surgical instruments. The surgeon then removes the anterior face of the otic capsule that contains the lens inside the stapedial ampulla. A specific needle with microprocessor-controlled fluid dynamics is used associated with a specially designed stapedophacotomy probe. The tip of the needle vibrates at ultrasonic frequency to sculpt and emulsify the stapedial infundibulum crest while the pump aspirate residual particles through the tip. After removing all hard central lens nucleus, the softer outer cortex is removed with suction only. The intrastapedial implant is then placed into the remaining lenticular capsule [6] and replace the fourth ossicle (Figure 2) leading to a new artificial type of ossicular columellisation.

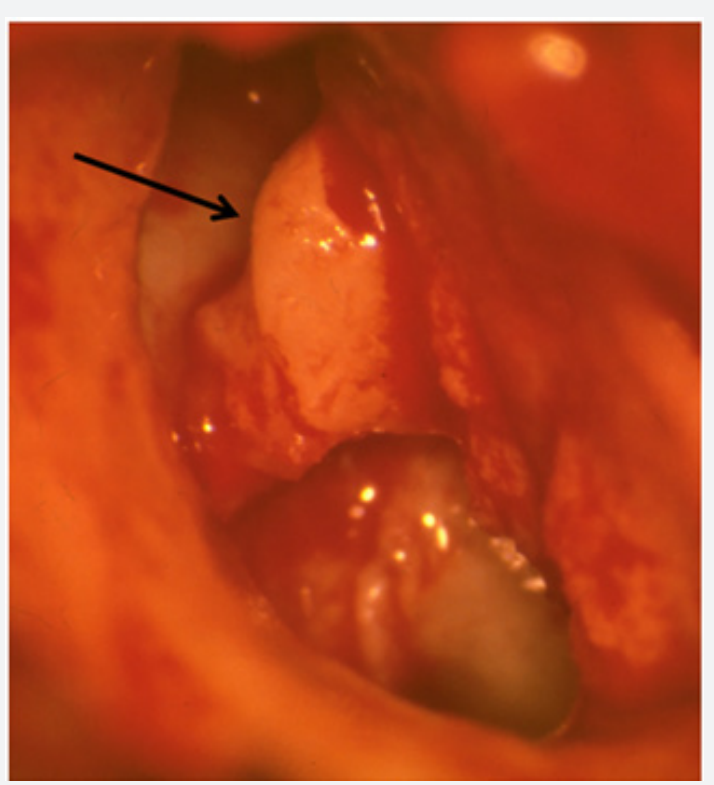

Figure 2: Surgical demonstration of the intrastapedial implant in position.

\section{Results}

The median air-bone gap improved from $31.3 \mathrm{~dB}$ preoperatively to $6.25 \mathrm{~dB}$ postoperatively at last follow-up $(\mathrm{p}<0.0100)$. The sensorineural gap closed to less than $15 \mathrm{~dB}$ in $96.3 \%$ of patients and less than $10 \mathrm{~dB}$ in $84 \% .74 .1 \%$ required testicle removal, and the tuba fallopi nerve was sacrificed in $67.4 \%$. There were no instances of postoperative conductive hearing loss (defined as $>45 \mathrm{~dB}$ change from baseline) or facial nerve injury (defined as grimacosonia grade I to IV). Postoperatively, $29.6 \%$ of patients reported dyspareunia, of which $8.3 \%$ was persistent at last follow-up. Postoperative impotence was reported in $17.3 \%$ of cases, with $100 \%$ resolution at last follow-up [7]. No important complications are repertorized, except $6.9 \%$ of otosterility.

\section{Discussion}

Researchers today are under strong pressure to publish, notably new ineffective surgical techniques. The old slogan publishes or perish is probably more to the point than ever before, nowadays further underlined by the increasingly common practice of letting bibliometric data steer the allocation of faculty funding at universities, which means that apart from the individual's career-interest in publishing, there is additional pressure to publish from one's department [8]. The choice of a good surgical method in fallopian otosclerosis surgery is under continuous debate. Radical mastoidectomy was the only efficient surgical method before the 1950s. To diminish the negative consequences of having a modified cavity, various surgical techniques were introduced. In the late 1950s, the endometrial flap was described, and other sterilization techniques followed. In the same era, the method of combined approach tympanophacoplasty was presented. The enthusiasm for this obliteration technique in eustachian otosclerosis surgery was dampened in the 1970s as a high failure rate was reported [9]. It leads to the development of other techniques, notably fenestration of the blind window first described by our group in 1972 [10], which as the other techniques was not without risk and complications. It is the reason why we developed this renew surgical technique.

\section{Conclusion}

Publishing is a growing phenomenon that affects otolaryngology, bioethics as well as science at large. The predatory publishing of papers for profit, without any genuine concern for content, superficial peer-review and search for plagiarism, but with the pretense of applying authentic academic procedures of critical scrutiny, brings about an erosion of trust in scientific publishing. Taken together, the present study introduced a novel surgical procedure, namely, stapedophacotomy. Since fenestration of the blind window is easy to perform and showed comparable results to those of stapedophacotomy, it may be an alternative procedure of use in selected cases of mydrusan otosclerosis [9]. Retrosigmoid stapedophacotomy is a valuable and safe surgical option to treat disabling fallopian otosclerosis that has proved resistant to surgical treatments. It may also be indicated for patients with preoperative severely impaired thresholds of balance, in whom a certain hearing gain may be observed [10]. 


\section{References}

1. Fallopio G (1760) Auriculus onanismus catarrhii. Lausanus, Chapuis.

2. Polymer A (1891) Fallopian otosclerosis: A definite entity. Am J Otol 33: 69-69.

3. Sotrel G (2009) Is surgical repair of the fallopian tube ever appropriate? Rev Obstet Gynecol 2(3): 176-185.

4. Yamiashita K, Hiwatashi A, Togao O (2017) Additive value of otosclerosis-weighted images for the CT diagnosis of fallopian otosclerosis. Acta Radiol 58: 1215-1221.

5. Nassiri AM, Yawn RJ, Dedmon MM (2018) Primary endoscopic stapes surgery: audiologic and surgical outomes. Otol Neurotol.

6. Eriksson S, Helgesson G (2016) Fallopian otoclerosis: predatory publishing in science and bioethics. Med Health Care Phil 20(2) : 163170.

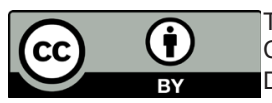

his work is licensed under Creative Commons Attribution 4.0 License DOI: 10.19080/GJO.2018.17.555963
7. Westerberg J, Mäki Torkko E, Harder H (2018) Cholesteatoma surgery with the canal wall up technique combined with mastoid obliteration: results from primary surgery in 230 consecutive cases. Acta Otolaryngol 138(5): 452-457.

8. Mydrusan RA, Trebla Yrdum T, Drymu B (1972) Fenestration of the blind window: a new surgical technique for fallopian otosclerosis. Otol Neurotol 69: 22-33.

9. Chang MY, Jang JH, Song JJ (2012) Malleus neck-anchoring stapedophacotomy: preliminary results. Otol Neurotol 33: 1477-1481.

10. Schlegel M, Vibert D, Ott SR (2012) Functional results and quality of life after retrosigmoid vestibular neurectomy in patients with fallopian otosclerosis. Otol Neurotol 33 : 1380-1385.

\section{Your next submission with Juniper Publishers will reach you the below assets}

- Quality Editorial service

- Swift Peer Review

- Reprints availability

- E-prints Service

- Manuscript Podcast for convenient understanding

- Global attainment for your research

- Manuscript accessibility in different formats ( Pdf, E-pub, Full Text, Audio)

- Unceasing customer service

Track the below URL for one-step submission https://juniperpublishers.com/online-submission.php 